\title{
Factors Associated With Changes in Self-Reported Dentifrice Consumption in a Brazilian Group from 1996 and 2009
}

\author{
Paulo Roberto Grafitti COLUSSI ${ }^{1}$ \\ Alex Nogueira HAAS ${ }^{2}$ \\ Rui Vicente OPPERMANN ${ }^{2}$ \\ Cassiano Kuchenbecker RÖSING ${ }^{2}$ \\ ${ }^{1}$ Department of Periodontology, UPF - University of Passo Fundo, Passo Fundo, RS, Brazil \\ ${ }^{2}$ Department of Periodontology, UFRGS - Federal University of Rio Grande do Sul, Porto Alegre, RS, Brazil
}

\begin{abstract}
The aim of the study was to determine factors associated with changes in self-reported dentifrice consumption in an urban population group over 13 years. This study evaluated two surveys of 671 and 688 households sampled in the urban area of a city from Southern Brazil in 1996 and 2009, respectively. The mother of the family was asked to answer a structured questionnaire about demographics, socioeconomic and behavioral variables. The primary outcome was obtained by questioning "how long does a dentifrice tube last in your house?" The cut-off point of duration was less than 1 month. It was used to determine high consumption of dentifrice (HCD). Associations between HCD and independent variables were evaluated by multivariable Poisson regression. There was a significant decrease of $20 \%(81.2 \%$ to $61.2 \%)$ in the prevalence of HCD between 1996 and 2009, resulting in a crude annual decrease of $1.54 \%$. Mother's age, family income, dental assistance, mother's brushing frequency and number of household members that use a toothbrush were significantly associated with HCD independent from the year of survey. The prevalence ratio (PR) of HCD for the year of survey was 0.75 , indicating an overall decrease of $25 \%$ in the probability of HCD from 1996 to 2009 . Probabilities of HCD also decreased over the 13 years among the strata of education, number of household members and reason for choice of dentifrice. It may be concluded that the factors associated with the observed decrease were higher educational levels, larger number of household members and reasons for choosing a dentifrice related to preventive/therapeutic effects.
\end{abstract}

Key Words: dentifrice, trend, risk factors, consumption.

\section{INTRODUCTION}

Improvements in oral health have been demonstrated around the world, with decreasing estimates of both caries and periodontal diseases. As regards to dental caries, this decline has occurred in developed (1) as well as in developing countries (2). In Brazil, for example, improvements in oral health were observed in all regions and in different socioeconomic strata $(3,4)$. The improvement in the epidemiological picture in terms of oral health has been related to several factors, including water fluoridation, different preventive programs and especially the widespread consumption of fluoridated dentifrice. For instance, the World Health Organization has elected the use of fluoride as a priority to achieve oral health, together with healthy dietary habits (5). However, only one preventive approach is common to virtually all countries that have experienced caries decline: the introduction of regular and widespread use of fluoridated dentifrice $(6,7)$.

Data of oral hygiene practices suggest that individuals are making efforts to improve oral health. In Brazil, most of the population reports good oral hygiene habits. The most cited toothbrushing frequency is three times a day, independent of the socioeconomic condition $(8,9)$. Despite the fact that self-reported oral hygiene practices do not necessarily indicate quality of oral hygiene, it should be emphasized that toothbrushing is always associated with dentifrice use. Therefore, it may be affirmed that the use of dentifrice is a universal

Correspondence: Prof. Dr. Cassiano K. Rosing, Rua Dr. Valle, 433/701, 90560-010 Porto Alegre, RS, Brasil. Tel/Fax: +55-51-3308-5318. e-mail: ckrosing@hotmail.com 
practice in Brazil.

The literature concerning consumption of dentifrice is scarce and the industry has been the main source of information, which is mostly related to market behavior. Studies evaluating factors that may determine dentifrice consumption in population groups are virtually inexistent in the literature. This reflects the lack of interest of the profession to describe and understand the practices and patterns of consumption related to one of the cores of oral health promotion. The study of dentifrice consumption is also important because its exaggerated consumption may be associated with adverse effects such as dental fluorosis and others $(10,11)$. Gjermo et al. (12) showed data from the market of oral hygiene products in Latin America revealing an increased consumption of toothbrushes, dental floss and dentifrice over the decades. Data from 1999 pointed that in Argentina, Chile and Brazil the consumption of dentifrice per capita per year was around $0.3,0.6$ and 0.4 $\mathrm{kg}$, respectively. In Brazil, an increase of approximately $0.2 \mathrm{~kg}$ of dentifrice consumption per capita was observed in a 5 -year period.

Trends of dentifrice consumption according to different socio-demographic and behavioral factors are unknown for population groups in Latin America. The aim of the present study was to determine factors associated with changes in self-reported dentifrice consumption in an urban population group in Southern Brazil between 1996 and 2009.

\section{MATERIAL AND METHODS}

The present trend study used data obtained from a major project that evaluated consumption of a variety of oral hygiene products at households in the urban area of Passo Fundo, RS, Brazil. Passo Fundo has approximately 190,000 inhabitants in a territorial area of $780 \mathrm{~km}^{2}$ located in Southern Brazil (13). More than $95 \%$ of the population lives in the urban area, with a $27.91 \%$ poverty index and a Gini Index of 0.41 (13).

The present study was reviewed and approved by the nstitutional Review Board on Ethics of the University of Passo Fundo. All participants were informed about the study, read and signed the informed consent form before being included in the study.

\section{Study Samples}

In 1996, a convenience sample of 868 households from Passo Fundo was obtained. At that moment, a standardized sampling methodology was defined to allow drawing future samples to study oral hygiene products consumption over time. In brief, 30 geographical areas of approximately $3 \mathrm{~km}^{2}$ were selected based on the map of the urban area of the city. In each area, districts and streets to be visited were determined, always in a central-peripheral direction. It was determined that 30 to 40 households would be included in each area to provide the estimated sample size. Households in which commercial activities and no living took place were not included. In order to be included, the household should have one of the three income ranges of interest in the present study: up to 2 Brazilian minimum wages (BMW), between 5 and 7 BMW and $>10$ BMW (13). Additionally, the mother or the head of family should be present in the moment of the interview.

In 2009, the same sampling procedure was applied and a sample of 1111 households was obtained. Data from the characteristics of the 2009 survey can be obtained in a previous publication (9).

For the analysis of the present study, households that did not present data relative to the analyzed variables and those that did not answer the question regarding dentifrice consumption (primary outcome of this study) were not included. 671 (77.3\%) and 688 (61.9\%) households were included for the survey years of 1,996 and 2009, respectively, totalizing 1,359 (68.7\%) included households.

\section{Sample Size}

The present study comprised a secondary analysis of two cross-sectional studies conducted to evaluate oral hygiene products consumption. The minimum sample size in 1996 was determined based on the expected proportion of self-reported consumption of dentifrice in a month. Since there are no previously published data on self-reported consumption of dentifrice in urban areas in Brazil, the sample size was determined considering the worst-case scenario. It was estimated that 625 households would be necessary to find a prevalence of $50 \%$ of high consumption of dentifrice considering an error of $4 \%$.

Post-hoc analyses demonstrated that this sample size provided sufficient power to fit multivariable Poisson regression models with up to 10 independent variables and $R^{2} \leq 0.2$. Power calculations were performed using $G^{*}$ Power 3.1 software. 


\section{Interview}

Heads of the family were interviewed using a structured questionnaire in order to obtain demographic, socioeconomic information, habits and knowledge related to oral health, and oral hygiene product consumption, especially dentifrice. Fieldwork teams were composed by three trained dentists that conducted the interviews. The same interviewer led the fieldwork in 1996 and 2009. Interviewers were informed about the research objectives, instructed in how the visits should be performed, trained in filling out the questionnaire before the study and used standardized procedures in order to increase consistency. Interviews were performed in the same time of each year (1996 and 2009), in June and July. Dentifrice consumption was assessed by the question "how long does a dentifrice tube last in your house?"

\section{Statistical Analysis}

Two assistants digitized the questionnaires into electronic files using a computer. Data set control was conducted by comparing the filled out questionnaires to the electronic files. Statistical analyses were performed using STATA software (STATA 10 for Macintosh; Stata Corp., College Station, TX, USA). The significance level was set at $5 \%$. The household was the unit of analysis for this study.

Dentifrice consumption was considered the dependent variable of the present study. Consumption was evaluated using the duration of one tube of dentifrice. Since there are no studies on the literature evaluating self-reported consumption of dentifrice in urban populations from Brazil, an arbitrarily defined cut-off point of duration less than one month was used to define high consumption of dentifrice (12).

Age, economic and educational levels, dental assistance, brushing frequency, number of household members that use a toothbrush and reason for choosing a dentifrice brand were socio-demographic and behavioral independent variables investigated in the present analysis. Economic level was determined using the family income and was categorized according to the BMW ( $>10$ BMW, 5-7 BMW and $\leq 2 \mathrm{BMW}$ ). Age, educational level and brushing frequency were based only on the mother of the family. Mother's educational level was categorized into high, medium and low according to years of education ( $\geq 12$ years, 8-11 years and $0-7$ years, respectively). The number of household members was based only in those members that use toothbrushes and was categorized into $1-2,3$ and $\geq 4$ members. The reason for choosing a dentifrice brand was dichotomized in therapeutic effect (presence of fluoride, anti-plaque or anti-calculus effect) and others (cost, preference, marketing or taste).

The prevalence of high consumption of dentifrice and $95 \%$ confidence intervals $(95 \% \mathrm{CI})$ were estimated for 1996 and 2009. Prevalence figures observed in 1996 and 2009 were compared according to independent variables. Comparisons of prevalence estimates were performed using Wald tests.

Poisson regression models with log link and robust variance estimator were fitted to study the association between socio-demographic and behavioral variables with high consumption of dentifrice. Main-effects models were fitted separately for each independent variable adjusting only for the surveyed year. Prevalence ratios (PR) and 95\% confidence intervals were reported.

Models including interaction terms between year of survey and each independent variable were fitted to quantify and compare the associations observed in 1996 and 2009. Significant interactions were found for mother's education, number of household members and reason for dentifrice choice. Three separate models were then fitted adjusting for mother's age.

Prevalence differences were estimated using Poisson regression models with identity link and robust variance estimator. Surveys from 1996 and 2009 were coded 0 and 13, respectively. Using this strategy, regression coefficients represent the annual prevalence difference of high consumption of dentifrice between 2009 and 1996. Annual prevalence differences were estimated according to mother's education, number of household members and reason for dentifrice choice in three separate models including interaction terms and adjusting for mother's age. Moreover, adjusted prevalence rates of high consumption for 1996 and 2009 were obtained from these models and plotted in graphs.

\section{RESULTS}

Overall, there were significant changes in demographic, socioeconomic and behavioral characteristics between 1996 and 2009, except for mother's brushing frequency and reason for choosing a dentifrice brand (Table 1). Family mothers were significantly older in 2009 compared to 1996. The percentage of households with family income $>10 \mathrm{BMW}$ 
decreased, whereas the percentage of family income $\leq 2$ BMW increased from 1996 to 2009. Education of family mothers improved in 2009 with an increase in the percentage of mothers with high educational level. There were no significant changes between 1996 and 2009 in the percentages of households with dental assistance either from private or public services. The percentage of households with $\geq 4$ members that brush their teeth was significantly lower in 2009 compared to 1996. Also, the mean number of household members that brush significantly decreased over the 13 years period.

Table 2 describes comparisons of the crude prevalence of high consumption of dentifrice in 1996 and 2009 according to demographics, socioeconomic

Table 1. Demographics, socioeconomic and behavioral data in 1996 and 2009.

\begin{tabular}{|c|c|c|c|c|c|}
\hline \multirow{2}{*}{ Variable } & \multicolumn{2}{|c|}{$1996(\mathrm{n}=671)$} & \multicolumn{2}{|c|}{$2009(n=688)$} & \multirow{2}{*}{$\mathrm{p}^{*}$} \\
\hline & $\%$ & $95 \% \mathrm{CI}$ & $\%$ & $95 \% \mathrm{CI}$ & \\
\hline \multicolumn{6}{|l|}{ Mother's age } \\
\hline$<35$ years & 30.4 & 26.9-33.9 & 22.2 & $19.1-25.4$ & $<0.001$ \\
\hline $35-49$ years & 48.1 & $44.4-51.9$ & 48.9 & $45.1-52.6$ & 0.80 \\
\hline$\geq 50$ years & 21.5 & $18.3-24.6$ & 28.9 & $25.5-32.3$ & 0.002 \\
\hline \multicolumn{6}{|l|}{ Family income } \\
\hline$>10 \mathrm{BMW}$ & 21.5 & $18.3-24.6$ & 14.8 & $12.2-17.5$ & 0.009 \\
\hline 5-7 BMW & 41.6 & $37.8-45.3$ & 41.3 & $37.6-44.9$ & 0.91 \\
\hline$\leq 2 \mathrm{BMW}$ & 36.9 & $33.3-40.6$ & 43.9 & $40.2-47.6$ & 0.002 \\
\hline \multicolumn{6}{|l|}{ Mother's education } \\
\hline High & 13.3 & $10.7-15.8$ & 23.4 & $20.5-26.9$ & $<0.001$ \\
\hline Medium & 54.7 & $50.9-58.5$ & 52.9 & $49.2-56.6$ & 0.50 \\
\hline Low & 32.0 & $28.5-35.6$ & 23.7 & $20.2-26.6$ & $<0.001$ \\
\hline \multicolumn{6}{|l|}{ Dental assistance } \\
\hline Private & 59.2 & $55.4-62.9$ & 59.1 & $55.5-62.3$ & 0.99 \\
\hline Public & 40.8 & $37.1-44.6$ & 40.9 & $37.2-44.5$ & 0.99 \\
\hline \multicolumn{6}{|l|}{ Mother's brushing frequency } \\
\hline $1-2$ times/day & 15.2 & $12.5-17.9$ & 12.9 & $10.4-15.4$ & 0.23 \\
\hline$\geq 3$ times/day & 84.8 & $82.0-90.0$ & 87.1 & $84.6-89.6$ & 0.23 \\
\hline \multicolumn{6}{|l|}{$\begin{array}{l}\text { Number of household } \\
\text { members that brush the teeth }\end{array}$} \\
\hline $1-2$ & 15.4 & $12.6-18.1$ & 28.8 & $25.4-32.3$ & $<0.001$ \\
\hline 3 & 27.2 & $23.9-30.6$ & 33.1 & $29.6-36.7$ & 0.02 \\
\hline$\geq 4$ & 57.4 & $53.6-61.1$ & 38.1 & $53.6-61.1$ & $<0.001$ \\
\hline \multicolumn{6}{|l|}{ Reason for dentifrice choice } \\
\hline Preventive/therapeutic effect & 13.3 & $10.7-15.8$ & 15.0 & $12.3-17.6$ & 0.36 \\
\hline Other (cosmetic, marketing) & 86.7 & $84.2-89.3$ & 85.0 & $82.4-87.7$ & 0.36 \\
\hline
\end{tabular}

*Wald test. and behavioral variables. Overall, there was a significant difference in the prevalence of high consumption of dentifrice between 1996 and 2009 with a decrease from $81.2 \%$ to $61.2 \%$. Statistically significant decreases in dentifrice consumption were also observed for all variables, except for households with mothers older than 50 years. Moreover, the pattern of dentifrice consumption reversed from 1996 to 2009 for mother's age, education and reason for choosing a dentifrice. Households with younger $(<35$ years) and higher-educated mothers and choosing dentifrices because of preventive/therapeutic effects had higher prevalence of high consumption of dentifrice in 1996. Conversely, households with middle-aged (35-49 years) and low-educated mothers and choosing dentifrices for cosmetic and marketing reasons had higher prevalence of dentifrice consumption in 2009.

Adjusted annual changes in the prevalence of high consumption of dentifrice estimated by Poisson regression models with identity link are presented in Table 3. The overall crude annual prevalence difference was -0.0154 indicating an annual decrease of $1.54 \%$ in the prevalence of high consumption. Annual changes remained significant for models of mother's education, number of household members that brush and reason for choosing a dentifrice brand. Figure 1 shows the adjusted prevalences for each stratum of education, number of household members and reason for dentifrice choice estimated from each model presented in Table 3. In all strata, the consumption of dentifrice decreased after 13 years. High and medium educational levels, as well as preventive/ therapeutic reasons for choosing a dentifrice, had higher impact on the decrease of dentifrice consumption as observed by the slope of fitted lines.

The prevalence ratio of high consumption per year of survey was 0.75 (95\% CI 0.70-0.81), indicating 
an overall decrease of $25 \%$ in the probability of high consumption of dentifrice in 2009 compared to 1996. Main effects Poisson regression models for sociodemographic and behavioral variables and the resulting prevalence ratios of high consumption of dentifrice adjusted for the year of the survey are shown in Table 4. Mother's age, family income, dental assistance, mother's toothbrushing frequency and number of household members that use a toothbrush were significantly associated with high consumption of dentifrice independently of the year of survey. Mother's education and reasons for choosing a dentifrice brand were not independently associated with dentifrice consumption. Households with 35-49 years-old mothers had 15\% higher probability of having high consumption of dentifrice than those with $\geq 50$ years-old mothers. The probability of high consumption of dentifrice was 1.18 and 1.28 times higher for households reporting family income of 5-7 and >10 BMW, respectively, compared to $\leq 2 \mathrm{BMW}$. Households with dental assistance provided by private services had higher probabilities of high consumption compared to those with public dental assistance. Mothers that reported brushing frequency $\geq 3$ times per day provided a probability $34 \%$ higher for the

Table 2. Crude prevalences of high consumption of dentifrice in 1996 and 2009 according to demographics, socioeconomic and behavioral variables.

\begin{tabular}{|c|c|c|c|c|c|c|}
\hline \multirow{2}{*}{ Variable } & \multicolumn{2}{|c|}{$1996(n=671)$} & \multicolumn{2}{|c|}{$2009(n=688)$} & \multirow{2}{*}{ Dif* } & \multirow{2}{*}{$\mathrm{p}^{* *}$} \\
\hline & $\%$ & $95 \% \mathrm{CI}$ & $\%$ & $95 \% \mathrm{CI}$ & & \\
\hline \multicolumn{7}{|l|}{ Mother's age } \\
\hline$<35$ years & 80.4 & $74.9-85.9$ & 51.6 & $43.7-59.9$ & -28.8 & $<0.001$ \\
\hline $35-49$ years & 86.7 & $83.0-90.4$ & 65.8 & $60.7-70.8$ & -20.9 & $<0.001$ \\
\hline$\geq 50$ years & 70.1 & $62.6-77.6$ & 60.8 & $54.0-67.6$ & -9.3 & 0.07 \\
\hline \multicolumn{7}{|l|}{ Family income } \\
\hline$>10$ BMW & 90.9 & $86.3-95.7$ & 70.6 & $61.7-79.5$ & -20.3 & $<0.001$ \\
\hline 5-7 BMW & 85.7 & $81.5-89.8$ & 63.7 & $58.1-69.3$ & -22.0 & $<0.001$ \\
\hline$\leq 2 \mathrm{BMW}$ & 70.6 & $64.8-76.3$ & 55.6 & $50.0-61.2$ & -15.0 & $<0.001$ \\
\hline \multicolumn{7}{|l|}{ Mother's education } \\
\hline High & 88.7 & $82.2-95.4$ & 59.5 & $51.9-67.1$ & -29.2 & $<0.001$ \\
\hline Medium & 82.8 & $78.9-86.7$ & 60.4 & $55.4-65.5$ & -22.4 & $<0.001$ \\
\hline Low & 75.3 & $69.6-81.1$ & 64.6 & $57.2-72.0$ & -10.7 & 0.03 \\
\hline \multicolumn{7}{|l|}{ Dental assistance } \\
\hline Private & 85.6 & $82.2-89.1$ & 63.1 & $58.4-67.8$ & -22.5 & $<0.001$ \\
\hline Public & 74.8 & $69.7-79.9$ & 58.4 & $52.6-64.1$ & -16.4 & $<0.001$ \\
\hline \multicolumn{7}{|l|}{ Mother's brushing frequency } \\
\hline $1-2$ times/day & 68.6 & $59.6-77.7$ & 40.4 & $30.2-50.7$ & -28.2 & $<0.001$ \\
\hline$\geq 3$ times/day & 83.5 & $80.4-86.5$ & 64.3 & $60.4-68.1$ & -19.2 & $<0.001$ \\
\hline \multicolumn{7}{|l|}{$\begin{array}{l}\text { Number of household } \\
\text { members that brush }\end{array}$} \\
\hline $1-2$ & 58.3 & $48.7-67.8$ & 37.9 & $31.1-44.7$ & -20.4 & $<0.001$ \\
\hline 3 & 78.7 & $72.7-84.6$ & 62.3 & $55.9-68.6$ & -16.4 & $<0.001$ \\
\hline$\geq 4$ & 88.6 & 85.4-91.8 & 77.9 & $72.8-82.9$ & -10.7 & $<0.001$ \\
\hline \multicolumn{7}{|l|}{ Reason for dentifrice choice } \\
\hline Preventive/therapeutic effect & 89.9 & $83.6-96.2$ & 53.4 & $43.7-63.1$ & -36.5 & $<0.001$ \\
\hline Other (cosmetic, marketing) & 79.9 & $76.6-83.2$ & 62.6 & $58.6-66.5$ & -17.3 & $<0.001$ \\
\hline Total & 81.2 & $78.3-84.2$ & 61.2 & $57.5-64.8$ & -20.0 & $<0.001$ \\
\hline
\end{tabular}

*Difference 2009-1996; **Wald test. 
household to have high consumption of dentifrice compared with brushing frequency 1-2 times per day. Households with 3 and $\geq 4$ members that use a

Table 3. Trends in dentifrice consumption from 1996 to 2009 estimated from interaction models adjusted by mother's age.

\begin{tabular}{lcccc}
\hline Model & Constant & Coefficient* & S.E. & $\mathrm{p}$ \\
\hline Crude model & 0.8122 & -0.0154 & 0.0018 & $<0.001$ \\
& & & & \\
$\begin{array}{l}\text { Education*Year } \\
\text { interaction model }\end{array}$ & 0.7131 & -0.0086 & 0.0037 & 0.02 \\
$\begin{array}{l}\text { Members*Year } \\
\text { interaction model }\end{array}$ & 0.5614 & -0.0159 & 0.0046 & 0.001 \\
$\begin{array}{l}\text { Reason*Year } \\
\text { interaction model }\end{array}$ & 0.8426 & -0.0282 & 0.0046 & $<0.001$ \\
\hline
\end{tabular}

*Coefficient represents the annual change in the prevalence of high consumption of dentifrice from 1996 to 2009.
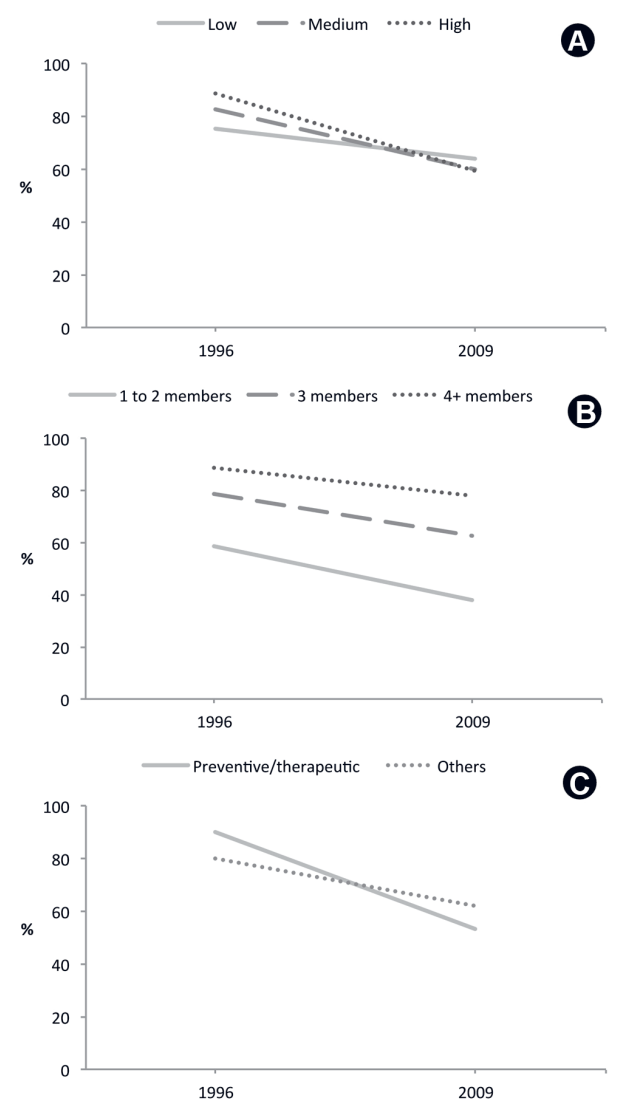

Figure 1. Adjusted prevalence of high consumption of dentifrice in 1996 and 2009 obtained from Poisson regression models with identity link. A: mother's education. B: number of household members. C: reason for choosing a dentifrice. toothbrush were $52 \%$ and $78 \%$ more likely to have high consumption, respectively, compared to 1-2 members. Prevalence ratios from models including interaction terms between year of survey and each independent variable, adjusted for mother's age, are shown in Table 5. In general, probabilities of high consumption of dentifrice decreased from 1996 to 2009 among the level of education, number of household members and reason for dentifrice choice.

\section{DISCUSSION}

The present study demonstrated a decrease in dentifrice consumption over a period of 13 years

Table 4. Main-effects models of high consumption of dentifrice for socio-demographic and behavioral variables adjusting for the year of survey.

\begin{tabular}{|c|c|c|c|}
\hline Variable & $\mathrm{PR}^{*}$ & $95 \% \mathrm{CI}$ & $\mathrm{p}$ \\
\hline \multicolumn{4}{|l|}{ Mother's age } \\
\hline$\geq 50$ years & 1 & & \\
\hline $35-49$ years & 1.15 & $1.05-1.26$ & 0.002 \\
\hline$<35$ years & 1.01 & $0.91-1.12$ & 0.89 \\
\hline \multicolumn{4}{|l|}{ Family income } \\
\hline$\leq 2 \mathrm{BMW}$ & 1 & & \\
\hline 5-7 BMW & 1.18 & $1.09-1.28$ & $<0.001$ \\
\hline$>10 \mathrm{BMW}$ & 1.28 & $1.17-1.39$ & $<0.001$ \\
\hline \multicolumn{4}{|l|}{ Mother's education } \\
\hline Low & 1 & & \\
\hline Medium & 1.03 & $0.96-1.11$ & 0.41 \\
\hline High & 1.05 & $0.95-1.16$ & 0.33 \\
\hline \multicolumn{4}{|l|}{ Dental assistance } \\
\hline Public & 1 & & \\
\hline Private & 1.12 & $1.04-1.20$ & 0.003 \\
\hline \multicolumn{4}{|l|}{ Mother's brushing frequency } \\
\hline $1-2$ times/day & 1 & & \\
\hline$\geq 3$ times/day & 1.34 & $1.18-1.53$ & $<0.001$ \\
\hline \multicolumn{4}{|l|}{ Number of household } \\
\hline members that brush & 1 & & \\
\hline $\begin{array}{l}1-2 \\
3\end{array}$ & 1.52 & $1.32-1.75$ & $<0.001$ \\
\hline $\begin{array}{l}3 \\
\geq 4\end{array}$ & 1.78 & $1.57-2.03$ & $<0.001$ \\
\hline \multicolumn{4}{|l|}{ Reason for dentifrice choice } \\
\hline Preventive/therapeutic effect & 1 & & \\
\hline Other (cosmetic, marketing) & 1.00 & $0.91-1.10$ & 0.95 \\
\hline
\end{tabular}

*Prevalence ratio. 
in households from an urban area of a city located in Southern Brazil. For instance, an annual decrease of $1.54 \%$ in the prevalence of high consumption of dentifrice and an overall decrease of $25 \%$ in the probability of this consumption were observed between 1996 and 2009. The decrease in dentifrice consumption was associated with educational level of the mother, number of persons living in the household that brush their teeth and declared reasons for choosing the toothpaste.

Studies assessing trends in oral hygiene products consumption are lacking in the dental literature. To the best of our knowledge, this is the first study to evaluate trends in dentifrice consumption in a Latin American population. On the other hand, there is a great amount of evidence on trends of dental caries (1-4), demonstrating that the prevalence of the disease has decreased over the past decades and it has been mostly influenced by the introduction and widespread use of fluoridated dentifrice $(10,11)$. Thus, it would be expected an increase in dentifrice use over the years paralleling the observed trends in the occurrence of oral diseases. Surprisingly, the present study demonstrated a decrease in dentifrice

Table 5. Multivariable models of high consumption of dentifrice including interaction terms and adjusting for mother's age.

\begin{tabular}{|c|c|c|c|}
\hline Variable & $\mathrm{PR}^{* *}$ & $95 \% \mathrm{CI}$ & $\mathrm{p}$ \\
\hline \multicolumn{4}{|l|}{ Model 1} \\
\hline \multicolumn{4}{|l|}{ Mother's education } \\
\hline 1996 / Low & 1 & & \\
\hline 1996 / Medium & 1.08 & $0.99-1.18$ & 0.10 \\
\hline 1996 / High & $1.15^{*}$ & $1.03-1.28$ & 0.01 \\
\hline 2009 / Low & $0.86^{*}$ & $0.75-0.98$ & 0.03 \\
\hline 2009 / Medium & $0.79 *$ & $0.71-0.88$ & $<0.001$ \\
\hline 2009 / High & $0.77 *$ & $0.67-0.89$ & 0.001 \\
\hline \multicolumn{4}{|l|}{ Model 2} \\
\hline $\begin{array}{l}\text { Number of household members } \\
\text { that brush the teeth }\end{array}$ & 1 & & \\
\hline 1996 / 1-2 members & $1.36^{*}$ & $1.13-1.63$ & 0.001 \\
\hline 1996 / 3 members & $1.51 *$ & $1.28-1.79$ & $<0.001$ \\
\hline $1996 / \geq 4$ members & $0.65 *$ & $0.51-0.83$ & $<0.001$ \\
\hline 2009 / 1-2 members & 0.79 & $0.71-0.89$ & 0.17 \\
\hline 2009 / 3 members & $0.88 *$ & $0.79-0.99$ & 0.02 \\
\hline \multicolumn{4}{|l|}{$2009 / \geq 4$ members } \\
\hline \multicolumn{4}{|l|}{ Model 3} \\
\hline \multicolumn{4}{|l|}{ Reason for dentifrice choice } \\
\hline 1996 / Preventive/therapeutic effect & 1 & & \\
\hline 1996 / Other (cosmetic, marketing) & $0.90 *$ & $0.83-0.98$ & 0.01 \\
\hline 2009 / Preventive/therapeutic effect & $0.60 *$ & $0.49-0.73$ & $<0.001$ \\
\hline 2009 / Other (cosmetic, marketing) & $0.78^{*}$ & $0.69-0.92$ & 0.01 \\
\hline
\end{tabular}

*Statistically significant. **Prevalence ratio. consumption over a 13-year period.-

In the present study, different demographic, socioeconomic and behavioral factors were associated with high consumption of dentifrice regardless of the year of survey. Higher prevalence ratios of high consumption were observed for mothers aged 3549 years, families with higher income ( $>10 \mathrm{BMW})$, households with private dental assistance, higher brushing frequency of the mother and higher number of members that use a toothbrush. The literature is scarce in data regarding factors associated to dentifrice consumption. Nevertheless, some cross-sectional studies have evaluated factors related to toothbrushing habits and oral care knowledge and attitudes. As regards the impact of economic status on dentifrice use, Kikwilu et al. (14) observed in Tanzania that cost was associated to lower frequency of dentifrice use. In China, it was observed that individuals from the lowest age groups presented better behavior related to toothbrushing (15). These findings are in accordance with those from the present study and, altogether, they emphasize that continuing education of the population is of great importance in order to impact the use of dentifrice towards a rational consumption, maximizing the potentials and minimizing the adverse effects of toothpastes. To the best of our knowledge there is no evidencebased information regarding what would be ideal dentifrice consumption. However, analytical studies, such as the present, point to differences observed in dichotomized data. Therefore, the observed decrease in excessive consumption is an interesting finding, which might decrease the unwanted adverse effects and also maximizing the cost-benefit relationship.

Changes in dentifrice consumption followed a different pattern according to the age of the mother of the household in the present study. The prevalence of high consumption of dentifrice decreased in the youngest and middle age group, whereas it did not change significantly in the oldest age group of mothers. Since education may be considered an increasing process, it is possible that the older women are less educated and less likely to change habits and improving together with the increasing knowledge of dentifrice consumption. In this regard, Feldens et al. (16) demonstrated that less educated mothers had a higher chance of implementing excessive consumption of fluoridated dentifrice for their children. Taking 
into account the above- mentioned considerations, the multivariable models of high consumption of dentifrice with interaction terms were adjusted for mother's age to control for a possible cohort effect in the present study.

The factors associated with changes in high consumption of dentifrice over the 13-year period were mother's education, number of household members that brush and reason for choosing a dentifrice. Mother's educational level has also been considered a predictor of dental caries and oral care behavior of children (1719). In regard to the number of household members, it was expected that the higher the number of persons living in a household, the higher the consumption of dentifrice. The association of these factors with dentifrice consumption over time may be explained, at least in part, by socioeconomic improvements occurred in Brazil over the past decades. Between 1996 and 2009, demographics of the surveyed samples changed significantly. In this 13-year period of evaluation, the age of the mothers increased and an improvement in the educational level was observed. These changes parallel the overall modifications in the economy that have occurred in Brazil during the studied period. In general, Brazilian economy has undergone major changes and became stronger. MW had major improvements and the educational level in the country has also increased. There was a shift in the socioeconomic status of the present sample and the MW increased from 70 to 238 American dollars between 1996 and 2009 (20,21).

The present study presents some limitations and strengths. Two consecutive cross-sectional surveys were studied in order to establish trends in dentifrice consumption. A longitudinal approach could also be used and would be less prone to criticism. However, time trend studies are well recognized to evaluate overtime changes in a variety of outcomes (22). Moreover, the analytical approaches applied in this study allowed determining longitudinal estimates of dentifrice consumption (23). These statistical strategies were also previously used by other researchers (24). Another important characteristic of the present study is that the 13-year observation period and the number of households included are both of considerable magnitude, increasing the possibilities of analyzing and extrapolating the results. Additionally, as the analytical unit was the household, each one included represents a higher number of involved persons, increasing the coverage of the findings. A limitation of the present study is that two non-representative samples were used and external validity may be questionable because of the selection bias. Nevertheless, representativeness was not the aim of the present study. This was an association study, and convenience samples have been used and considered appropriate for analytical approaches similar to the present one (25).

Future studies in this and other populations may provide additional information on dentifrice consumption over time and if the trend found in the present study will be maintained or will change in the following decades. In the meanwhile, the present data indicate that dentifrice consumption decreased in this Brazilian sample. The factors associated with this decrease were higher educational levels, higher number of household members that brush their teeth and reasons for choosing a dentifrice related to preventive/ therapeutic effects.

\section{RESUMO}

O objetivo deste estudo foi determinar fatores associados com mudanças no consumo auto-reportado de dentifrício em um grupo populacional urbano ao longo de 13 anos. Este estudo avaliou dois levantamentos de 671 e 688 domicílios selecionados na área urbana de uma cidade do sul do Brasil em 1996 e 2009 , respectivamente. A mãe da família respondeu a um questionário estruturado sobre variáveis demográficas, socioeconômicas e comportamentais. O desfecho primário foi obtido questionando "quanto tempo um tubo de dentifrício dura na sua casa?". O ponto de corte de duração foi menor que um mês. Este foi utilizado para determinar alto consumo de dentifrício (ACD). Associações entre ACD e variáveis independentes foram avaliadas por regressão de Poisson multivariada. Houve uma diminuição significativa de $20 \%$ (81,2\% para 61,2\%) na prevalência de ACD entre 1996 e 2009, resultando em um decréscimo anual não ajustado igual a 1,54\%. Idade da mãe, renda familiar, assistência odontológica, frequência de escovação da mãe e número de membros no domicílio que escovam os dentes estiveram significativamente associados com ACD independentemente do ano de levantamento. A razão de prevalência (RP) do ACD para ano de levantamento foi 0,75 , indicando uma diminuição geral de $25 \%$ na probabilidade de ACD entre 1996 para 2009. As probabilidades de ACD também diminuíram ao longo de 13 anos entre os estratos de educação, número de membros da família e razões para escolha do dentifrício. Pode-se concluir que os fatores associados com a diminuição observada foram maior nível educacional da mãe, maior número de membros da família e razões para escolha do dentifrício relacionadas a efeitos preventivo/terapêuticos.

\section{REFERENCES}

1. WHO. The World Oral Report 2003. Continuous improvement of oral health in the 21 st century - the approach of the WHO Global Oral Health Programme. Geneve: World Health Organization; 2003.

2. Bonecker M, Cleaton-Jones P. Trends in dental caries in Latin American and Caribbean 5-6 and 11-13-year-old children: a 
systematic review. Community Dent Oral Epidemiol 2003;31:152 157.

3. Carvalho JC, Figueiredo MJ, Vieira EO, Mestrinho HD. Caries trends in Brazilian non-privileged preschool children in 1996 and 2006. Caries Res 2009;43:2-9.

4. Constante HM, Bastos JL, Peres MA. Trends in dental caries in 12-and 13-year-old schoolchildren from Florianópolis between 1971 and 2009. Braz J Oral Sci 2010;9:410-414.

5. Petersen PE. Global policy for improvement of oral health in the $21^{\text {st }}$ century - implications to health research of World Health Assembly 2007, World Health Organization. Community Dent Oral Epidemiol 2009;37:1-8.

6. Jackson RJ, Newman HN, Smart GJ, Stokes E, Hogan JI, Brown $\mathrm{C}$, et al.. The effects of a supervised toothbrushing programme on the caries increment of primary school children, initially aged 5-6 years. Caries Res 2005;39:108-115.

7. Cury JA, Tenuta LMA, Ribeiro CC, Paes Leme AF. The importance of fluoride dentifrices to the current dental caries prevalence in Brazil. Braz Dent J 2004;15:167-174.

8. Abegg C. Oral hygiene habits among Brazilian adults in an urban area of Southern Brazil. Rev Saúde Pública 1997;31:586-593.

9. Colussi PRG, Haas AN, Oppermann RV, Rösing CK. Consumption of toothpaste and associated factors in a Brazilian population group. Cad Saúde Pública 2011;27:546-554.

10. Wong MC, Clarkson J, Glenny AM, Lo EC, Marinho VC, Tsang BW, et al.. Cochrane reviews on the benefits/risks of fluoride toothpastes. J Dent Res 2011;90:573-579.

11. West NX, Moran JM. Home-use preventive and therapeutic oral products. Periodontol 2000 2008;48:7-9.

12. Gjermo P, Rösing CK, Susin C, Oppermann RV. Periodontal diseases in Central and South America. Periodontol 2000 2002;29:70-78

13. Brazilian Institute of Geography and Statistics. Ministry of Planning, Budget and Management. Cities@ 2009. Rio de Janeiro, Brazil; 2009

14. Kikwilu EN, Frencken JE, Mulder J. Utilization of toothpaste and fluoride content in toothpaste manufactured in Tanzania. Acta
Odontol Scand 2008;66:293-299.

15. Peng B, Petersen PE, Tai BJ, Yuan BY, Fan MW. Changes in oral health knowledge and behaviour 1987-95 among inhabitants of Wuhan, PR China. Int Dent J 1997;47:142-147.

16. Feldens CA, Giugliani ERJ, Vigo À, Vítolo MR. Early feeding practices and severe early childhood caries in four-year-old children from Southern Brazil: a birth cohort study. Caries Res 2010;44:445-452.

17. Pereira I, Ekanayake L. Factors influencing perception of oral health among adolescents in Sri Lanka. Int Dent J 2008;58:349355 .

18. Grembowski D, Spiekerman C, Milgrom P. Linking mother access to dental care and child oral health. Community Dent Oral Epidemiol 2009;37:381-390.

19. Piovesan C, Mendes FM, Ferreira FV, Guedes RS, Ardenghi TM. Socioeconomic inequalities in the distribution of dental caries in Brazilian preschool children. J Public Health Dent 2010;70:319326.

20. Brazilian Institute of Geography and Statistics. Ministry of Planning, Budget and Management. Sustainable Development Indicators 2010. Rio de Janeiro, Brazil; 2010.

21. Brazilian Institute of Geography and Statistics. Ministry of Planning, Budget and Management. Demographic Census 2010. Rio de Janeiro, Brazil, 2010.

22. Rothman KJ, Greenland S, Lash TL. Modern Epidemiology. Lippincott, Williams, \& Wilkins; 2008.

23. Diggle PJ. Time series: a biostatistical introduction. Oxford: Oxford University Press; 1992.

24. Celeste RK, Nadanovsky P, Fritzell J. Trends in socioeconomic disparities in oral health in Brazil and Sweden. Community Dent Oral Epidemiol 2011;39:204-212.

25. Beck JD. Risk revisited. Community Dent Oral Epidemiol 1998;26:220-225. 